\title{
Identificación de Salmonella y Escherichia coli en manos y guantes de manipuladores en planta de sacrificio y faenado de un municipio de Cundinamarca
}

\author{
Lucía Constanza Corrales Ramírez MSc ${ }^{1}$, Verónica Angel Peña², \\ Diana Karolina Caicedo Velásquez ${ }^{2}$.
}

1. Docente Investigador Universidad Colegio Mayor de Cundinamarca.
2. Estudiantes del Programa de Bacteriología y Laboratorio Clínico de la Universidad Colegio Mayor de Cundinamarca.

Correspondencia: Icorralesr07@gmail.com

Recibido: 10-03-08 / Aceptado: 05-05-08

\section{Resumen}

La presencia y consumo de alimentos contaminados con microorganismos patógenos en el hombre, tiene una alta incidencia en países en vía de desarrollo, en donde el tratamiento de dichas enfermedades tiene como consecuencia un impacto importante para el sistema de salud pública. El objetivo de este proyecto fue investigar la presencia de Salmonella y Escherichia coli en 40 muestras provenientes de los guantes y las manos de los operarios de bovinos y porcinos de una planta de sacrificio y faenado de un municipio de Cundinamarca, Colombia, por medio de cultivo microbiológico y pruebas bioquímicas. La metodología incluyó la aplicación de una encuesta de indagación sobre aspectos relacionados con el conocimiento y aplicación de normas higiénico-sanitarias y buenas prácticas de manufactura, la siembra de las muestras en caldo nutritivo, el aislamiento de los bacilos Gram negativos en agar Mac Conkey, Endo y XLD, la verificación microscópica con coloración de Gram a las 24 horas y la identificación con pruebas bioquímicas. Los resultados permitieron confirmar la presencia de una variedad significativa de agentes bacterianos implicados en contaminación en cárnicos como E. coli, y la ausencia de Salmonella spp. A partir del estudio, se recomendó optimizar la aplicación de las normas higiénico-sanitarias y de bioseguridad con el fin de ofrecer productos saludables para el consumo humano.

Palabras clave: contaminación, Escherichia coli, infección, productos cárnicos, Salmonella, salud pública.

\section{Abstract \\ Identification of Salmonella and Escherichia coli in hands and gloves of meat handlers in a slaughterhouse in a municipality in Cundinamarca}

The presence and consumption of food contaminated with pathogenic microorganisms for humans has a high incidence in developing countries, where the treatment of these diseases has as a consequence an important impact for the public health system. The objective of this project was to investigate the presence of Salmonella and Escherichia coli in 40 samples from the hands of the employees working with cattle, pigs and from their gloves in a slaughterhouse in a municipality in Cundinamarca, Colombia, by means of microbiological culture and biochemical tests. The methodology was an investigation survey on aspects such as the knowledge and application 
of sanitary and hygiene norms and good practices of manufacture, planting of the samples in a broth, isolation of the negative Gram bacilli in agar Mac Conkey, XLD and agar Endo, microscopic verification with coloration of Gram to the 24 hours, and identification with biochemical tests. The results allowed us to confirm the presence of a significant variety of implied bacteriological contaminating agents in meat like E. coli, and the absence of Salmonella spp. From the study, it was recommended to optimize the application of the hygiene and bio safety norms with the purpose of offering healthful products for human consumption.

Key words: contamination, Escherichia coli, infection, meat products, public health, Salmonella.

\section{Introducción}

En Colombia la normatividad contempla en el Decreto 3075 de 1997 que la carne y los productos cárnicos se encuentran dentro del grupo de alimentos considerados de mayor riesgo en salud pública y se establece que la salud es un bien de interés público, por lo cual se dictan disposiciones contenidas en decretos de orden público que regulan todas las actividades que puedan generar factores de riesgo por el consumo de alimentos (1).

El artículo 34 de la Ley 1122 de 2007 dispone que es competencia exclusiva del Instituto Nacional de Vigilancia de Medicamentos y Alimentos (INVIMA), la inspección, vigilancia y control de las plantas de beneficio de animales, por lo cual se evidencia la necesidad de tomar medidas que permitan garantizar la calidad de estos productos alimenticios, con el fin de proteger la salud humana y prevenir posibles daños (2)

El Ministerio de la Protección Social, con el Decreto Número 1500 del 4 de mayo de 2007, establece el reglamento técnico a través del cual se crea el sistema oficial de inspección, vigilancia y control de la carne, productos cárnicos comestibles y derivados destinados para el consumo humano y los requisitos sanitarios y de inocuidad que se deben cumplir en su producción primaria, beneficio, desposte, desprese, procesamiento, almacenamiento, transporte, comercialización, expendio, importación o exportación (3).

La industria de producción de carne es un sector importante en el país, representa el 1,8\% de la producción bruta generada por el total de la industria manufacturera nacional y el 6,8\% de la industria de alimentos, genera alrededor de 10.000 empleos directos al año y abastece con producción nacional el consumo interno, ya que para el comercio exterior esta producción ha sido limitada (4).
Sin embargo, se prevé un panorama positivo para este sector, tanto en el consumo interno, como en el de las exportaciones de productos cárnicos higiénicos y saludables. Actualmente PROEXPORT y la Federación Nacional de Ganaderos - FEDEGAN, apoyan actividades que generen el desarrollo de la capacidad exportadora competitiva del sector cárnico, especialmente de la carne deshuesada congelada y refrigerada, empacada al vacío, a los mercados de Venezuela, Antillas Holandesas y Aruba; y de la consolidación de las exportaciones hacia Perú (5). Por lo tanto es necesario que los empresarios y gremios del sector desarrollen acciones para el fortalecimiento de: la trazabilidad en toda la cadena; la tecnificación y certificación del Sistema de Análisis de Peligros y Puntos de Control Crítico (HACCP) de las plantas de beneficio; los sistemas de clasificación de canales y de infraestructura portuaria para exportación, entre otros (5).

Los productos cárnicos, considerados como la principal fuente de proteína para los humanos, son también el vehículo más frecuente en la producción de intoxicación alimentaría, como consecuencia de un inadecuado sistema de calidad higiénico sanitario en los procesos de sacrificio y faenado animal. El ganado sano alberga diversos patógenos tales como Escherichia coli, Salmonella spp. y Listeria spp, entre otros, los cuales se encuentran habitualmente como flora normal en tracto gastrointestinal, piel y pezuñas (6). Los tejidos internos de la carne en canal se consideran estériles, característica que se ve alterada si no se aplican las adecuadas prácticas de manufactura durante los procesos de sacrificio y faenado de la canal, lo que conlleva a contaminación con suciedad, materia fecal y polvo, entre otros, situación que es directamente proporcional al uso de las normas higiénicosanitarias en la planta de procesamiento. 
Las enfermedades transmitidas por alimentos ocurren en un gran porcentaje porque éstos han sido contaminados por el personal encargado de su manipulación durante el proceso y con consecuencias a nivel de salud pública (7). Se pueden distinguir dos tipos de afecciones de origen bacteriano transmitidas al hombre: la enfermedad, entendida esta como los desequilibrios provocados por los organismos patógenos transferidos por medio de los alimentos; la infección, que se provoca a partir de la ingesta de microorganismos patógenos específicos (bacterias, virus, hongos y parásitos), que posteriormente se multiplican en el intestino, tejido en el cual producen toxinas; y la intoxicación alimenticia, la cual se produce por la ingesta directa de toxinas bacterianas como resultado del proceso del metabolismo de estos agentes contaminantes en los alimentos o tejidos animales con destino al consumo humano (7).

E.coli y Salmonella spp. son responsables de toxoinfecciones alimentarias generadas a partir del consumo de productos cárnicos contaminados (8), definiendo éstas como la ocurrencia de dos o más casos de una enfermedad similar producida por la ingestión de un alimento común (7). Escherichia coli pertenece a la flora normal del intestino humano, de ésta se conocen hasta el momento seis serotipos que pueden ser patógenos y causar daño produciendo diferentes cuadros clínicos, entre ellos diarrea, síndrome urémico hemolítico, colitis hemorrágica y cuadros de disentería (8). Este microorganismo se clasifica en base al grado de patogenicidad y manifestaciones clínicas en: enterotoxigénica (ETEC), enterohemorrágica (EHEC), enteroinvasiva (EIEC), enteropatógena (EPEC), enteroagregativa, (EAEC) y de adherencia difusa (DAEC) $(9,10)$.

Salmonella spp. se considera como "Patógeno Universal" debido a que cuenta con mecanismos de adaptación a diversas condiciones ambientales y por tanto posee una amplia distribución en el medio $(9,11,12)$. Se identifican dos tipos de Salmonellosis humanas: las debidas a serotipos estrictamente humanos, que causan síndromes tifoideos con presencia de bacterias en sangre, y las ocasionadas por serotipos ubicuos, que provocan diarrea, vómitos y fiebre $(9,13,14)$. Salmonella spp. es responsable de un amplio número de manifestaciones clínicas en los seres humanos como: fiebres entéricas, gastroenteritis, bacteriemia, infecciones localizadas y estado de portador crónico. Se transmite por la ingesta de microorganismos presentes en alimentos provenientes de animales infectados, o contaminados con las heces de un animal o persona infectada $(9,10,11)$.

Actualmente el sistema de salud colombiano a partir de reformas como la ley 100 del 93 y en cabeza del Ministerio de la Protección Social se crea un sistema de vigilancia en salud publica denominado SIVIGILA en el cual a través del Instituto Nacional de Salud (INS) se notifican casos de intoxicación alimentaria o con agua, por medio de tablas de notificación semanal obligatoria. Al año 2007 se reportaron en total 5563 casos con una mayor incidencia en los departamentos de Antioquia, Caldas, Valle, Santander, Cundinamarca y la cuidad de Bogotá. En primer el trimestre del año 2008 se han reportado 759 casos asociados a intoxicación alimentaria presentando mayor incidencia en los departamentos de Antioquia, Cundinamarca, Magdalena y la ciudad de Bogotá (7).

Esta investigación se propuso determinar la presencia de agentes patógenos para el hombre (agentes específicos como Salmonella y E. coli), indicadores de la presencia de riesgo biológico para la salud humana en cárnicos, que provienen de contaminación generada en el proceso de manipulación por parte de los operarios de una planta de sacrificio y faenado de un municipio de Cundinamarca, Colombia. Otro objetivo fue detectar las falencias en la aplicación de las normas y proponer estrategias que apunten a brindar una mayor eficiencia y competitividad sanitaria del producto.

\section{Materiales y métodos}

El estudio se inició con el reconocimiento de la planta física, el talento humano y servicios con que cuenta la planta de faenado. Se estructuró un instrumento, tipo encuesta de indagación por medio de preguntas cerradas y abiertas, relacionadas con el conocimiento y aplicación de normas higiénico - sanitarias y buenas prácticas de manufactura, con el propósito de conocer algunos aspectos específicos relacionados con la contaminación de los productos cárnicos y en concordancia con el Decreto 3075 de 1997, en el cual se establece que los manipuladores de alimentos deben cumplir tres aspectos para garantizar buenas prácticas de manufactura que son: estado de salud, 


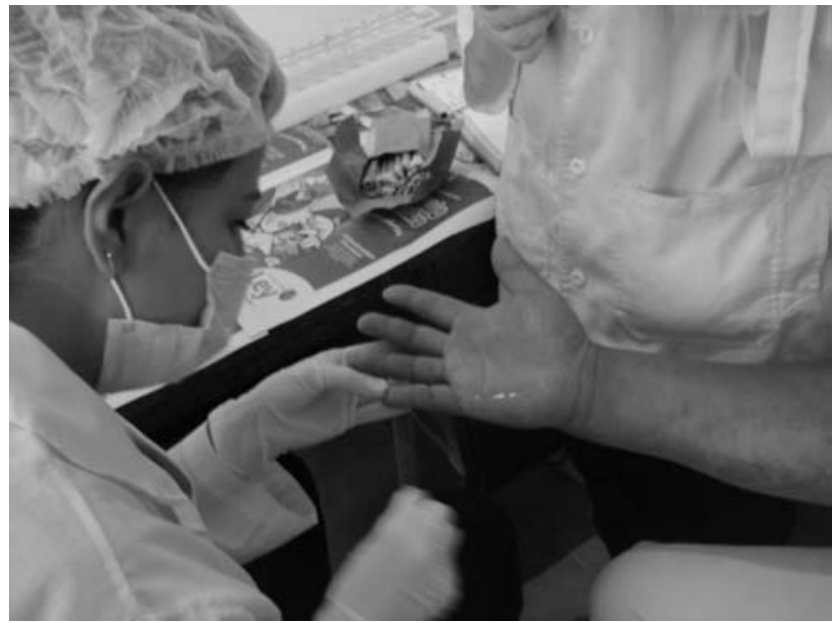

Figura 1. Toma de muestra en manos.

educación y capacitación, prácticas higiénicas y medidas de protección (1).

Para la toma de las muestras en la planta se aplicaron las normas de bioseguridad y asepsia correspondientes para el procedimiento. Se eligieron 20 operarios de la planta correspondientes a la totalidad de la población encargada de la manipulación de carne bovina y porcina para el estudio bacteriológico. Se realizó la toma de dos muestras seriadas, provenientes de las manos en los operarios de porcinos y de los guantes en los operarios de bovinos. La primera toma en cada caso se realizó al inicio de las labores y la segunda durante el proceso en la planta de sacrificio. Para la toma de las muestras los operarios no debían efectuar ningún lavado de manos o de guantes, ni utilizar agentes desinfectantes. La obtención de las muestras se realizó con un escobillón estéril, en caldo nutritivo y caldo tetrationato selectivo para Salmonella (9).

El tipo de técnica utilizada fue toma de muestra, al mismo operario, por barrido/frotis de manos y/o guantes con escobillón estéril en dos momentos diferentes. La primera toma se realizó al inicio de labores de los operarios, la segunda, transcurridas dos horas después del inicio de las mismas. Se tomaron 40 muestras en total (20 antes y 20 durante las labores que desempeña cada operario dentro de la planta).

El escobillón se introdujo en los tubos que contienen caldo nutritivo y tetrationato, se transportaron al Laboratorio de Microbiología de La Universidad Colegio Mayor de Cundinamarca para incubar por 24 horas. Posterior a este tiempo se realiza lectura macroscópica de la presencia de turbidez en el medio líquido y coloración

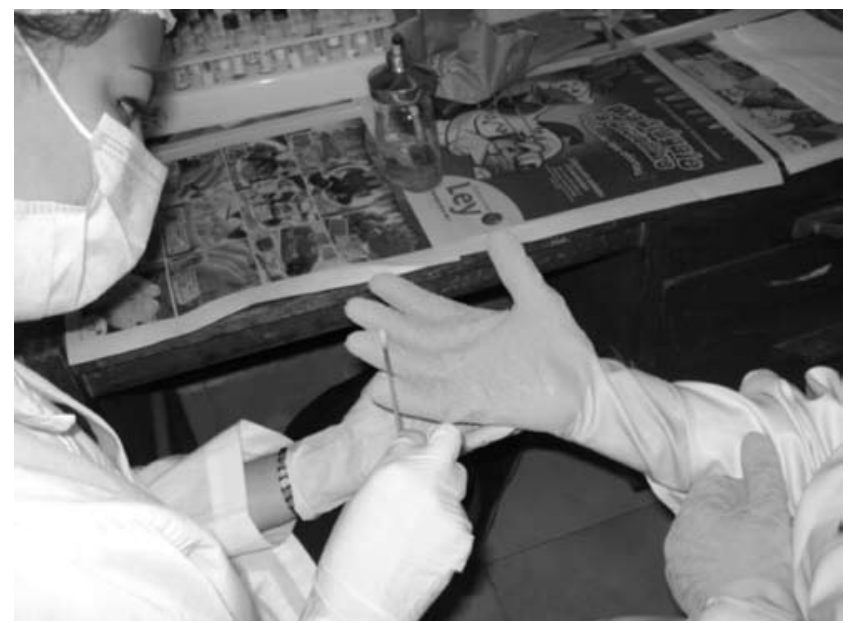

Figura 2. Toma de muestra en guantes.

de Gram, para verificar el crecimiento bacteriano. Las muestras positivas, aquellas en las cuales se observó desarrollo bacteriano, se sembraron en agares Endo y Mac Conkey, medios selectivos para bacilos Gram negativos y coliformes y agar XLD selectivo para bacterias enteropatógenas, Figuras 3 y 4 (9).

Los tubos con caldo tetrationato no mostraron desarrollo bacteriano. Posteriormente se realizó la lectura de las características macroscópicas del crecimiento en las placas de agar, obteniendo diversidad en las reacciones bioquímicas de la flora bacteriana Gram negativa aislada y coloración de Gram para verificar la pureza del cultivo. Para identificar los agentes bacterianos aislados se procedió a realizar prueba de oxidasa según el caso y las pruebas bioquímicas (TSI, LIA, MIO, ornitina, lisina, arginina, urea, fenil alanina, rojo de metilo, citrato de Simmons, caldo MR, VP y azúcares), Figura 5 (9).

\section{Protocolo establecido para el estudio}

\section{Resultados}

Entre agosto a noviembre de 2007 se encuestaron a 20 operarios de la Planta de Sacrificio y Faenado de un municipio de Cundinamarca, con el fin de determinar el nivel de conocimiento del personal acerca de las buenas prácticas de manufactura y normas de bioseguridad, además de las acciones llevadas a cabo por parte de la planta en cuanto a la capacitación permanente de su personal y a la vigilancia de la salud de los mismos. Se tomaron 40 muestras para el estudio experimental. Las encuestas y los datos obtenidos se procesaron mediante 


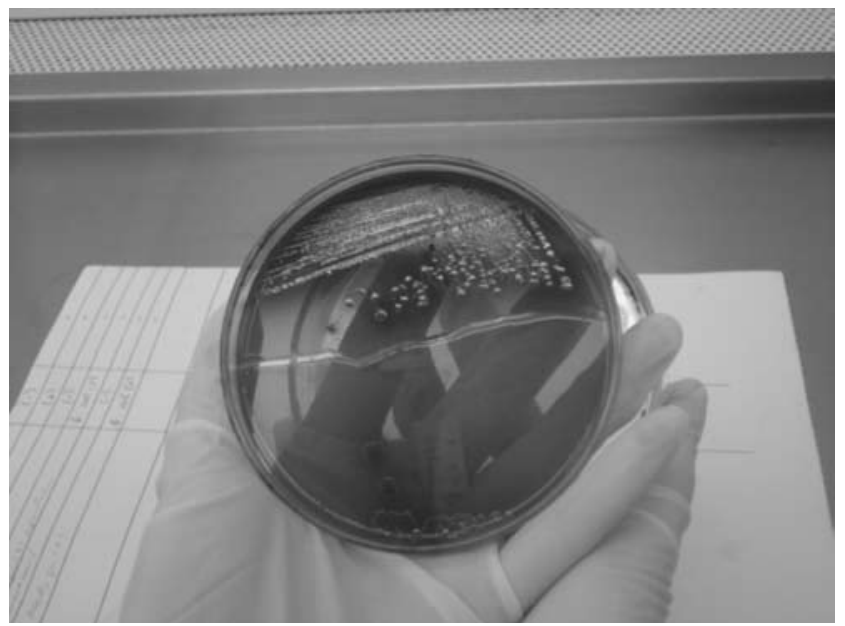

Figura 3. Agar Endo con reacción positiva para fermentación de lactosa.

el método estadístico básico descriptivo y los resultados se expresaron en porcentaje.

La encuesta indagó sobre diferentes aspectos, en primera instancia el lavado de manos, requisito de gran importancia al inicio de labores y al entrar o salir del área asignada. En cuanto a este aspecto el $35 \%$ de la población lo realiza con agua y jabón antibacterial, el 30\% utiliza agua, jabón y una solución desinfectante, el $25 \%$ realiza el lavado con agua y jabón cosmético y un $10 \%$ únicamente con agua.

En cuanto al conocimiento de las buenas prácticas de manufactura, el $90 \%$ de la población manifestó conocerlas y el $10 \%$ restante afirma no conocerlas. En lo relacionado con la capacitación que han recibido sobre las buenas prácticas de manufactura, el $45 \%$ de la población encuestada refiere haberse capacitado a través del SENA, el $40 \%$ por medio de cursos externos a la planta, ambas realizadas de una a dos veces al ańo y el $15 \%$ restante no responde la pregunta.

En lo referente al conocimiento sobre los agentes de contaminación en productos cárnicos, se observa que el $30 \%$ afirma que ésta se presenta por agentes bacterianos, el $20 \%$ por contacto con utensilios de trabajo contaminados, el $10 \%$ por agentes virales, $10 \%$ por agentes parasitarios y un $30 \%$ no responden a la pregunta.

En la indagación relacionada con los exámenes de salud ocupacional, el $80 \%$ de la población encuestada manifiesta que estos exámenes son llevados a cabo en la planta de sacrificio cada seis meses, el $10 \%$ que son realizados cada tres meses, el $5 \%$ que son realizados cada año y un 5\% anotan nunca haberse realizado dichos exámenes.

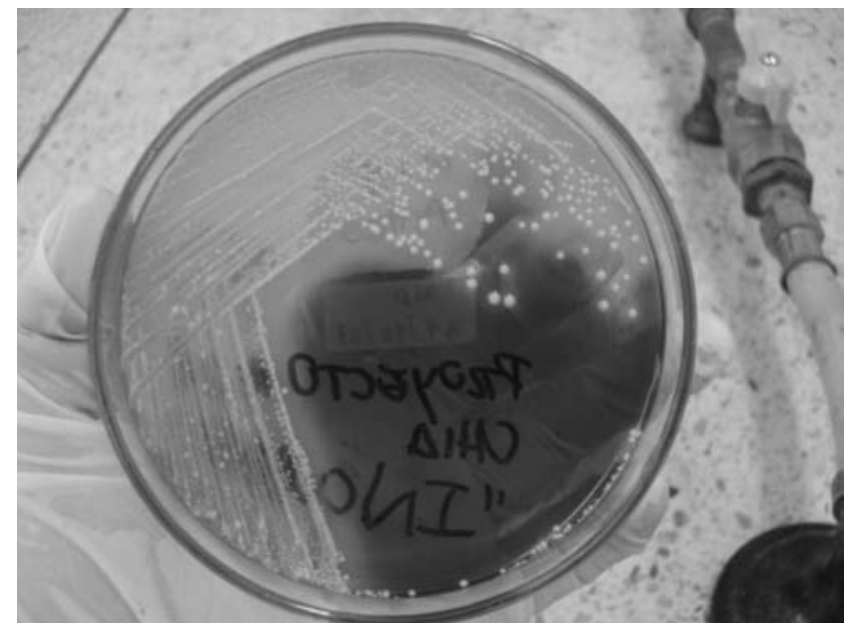

Figura 4. Agar XLD con reacción positiva para fermentación de carbohidratos.

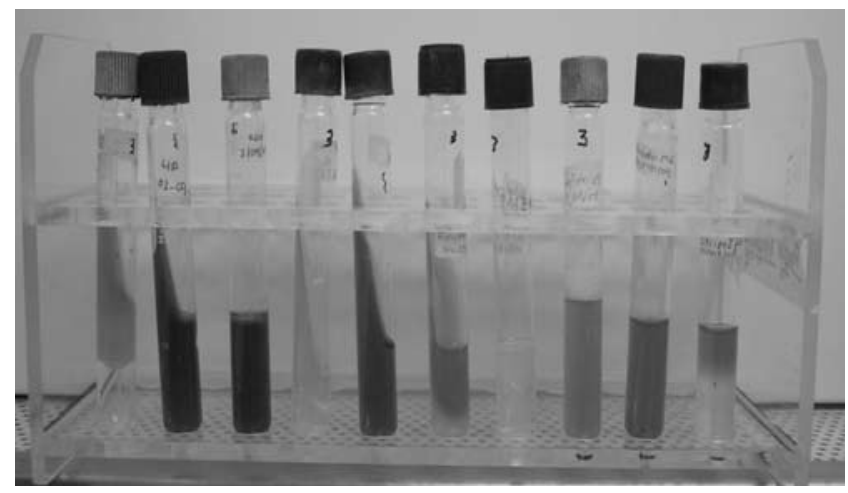

Figura 5. Pruebas bioquímicas Escherichia coli.

En cuanto al uso y función de los elementos de bioseguridad, el $25 \%$ de la población encuestada afirma que la función de los elementos de bioseguridad es brindar protección personal, un 25\% afirma que son elementos de dotación, un $20 \%$ que se utilizan para evitar contaminación y un 30\% no responde a la pregunta. En cuanto a los elementos de bioseguridad que utilizan, el $100 \%$ de la población manifiesta utilizar tapabocas, gorro, guantes, overol y botas.

El estudio microbiológico, en la primera toma de muestra, la cual se llevó a cabo al inicio de las labores, se observó en los caldos nutritivos desarrollo de flora mixta, conformada de acuerdo con su morfología por: cocos Gram positivos, bacilos Gram negativos y bacilos Gram positivos. Las muestras con bacilos Gram negativos se aislaron en placas de agar Mac Conkey, Endo y XLD, a las cuales se les realizó lectura de características macroscópicas, verificación microscópica de pureza y prueba de oxidasa según el caso y el montaje de pruebas bioquímicas. Los resultados obtenidos se muestran en la Figura 6. 


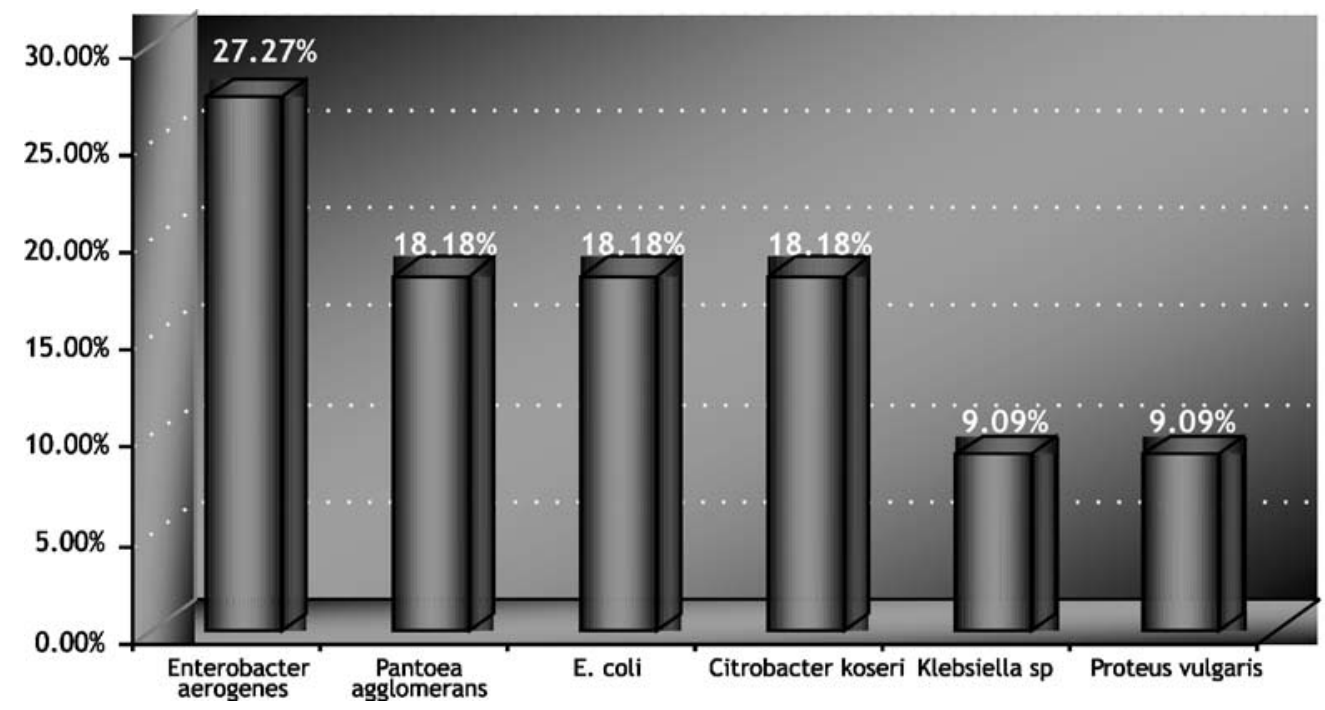

Figura 6. Identificación de microorganismos Gram negativos, baterías bioquímicas antes del inicio de labores en la planta de sacrificio.

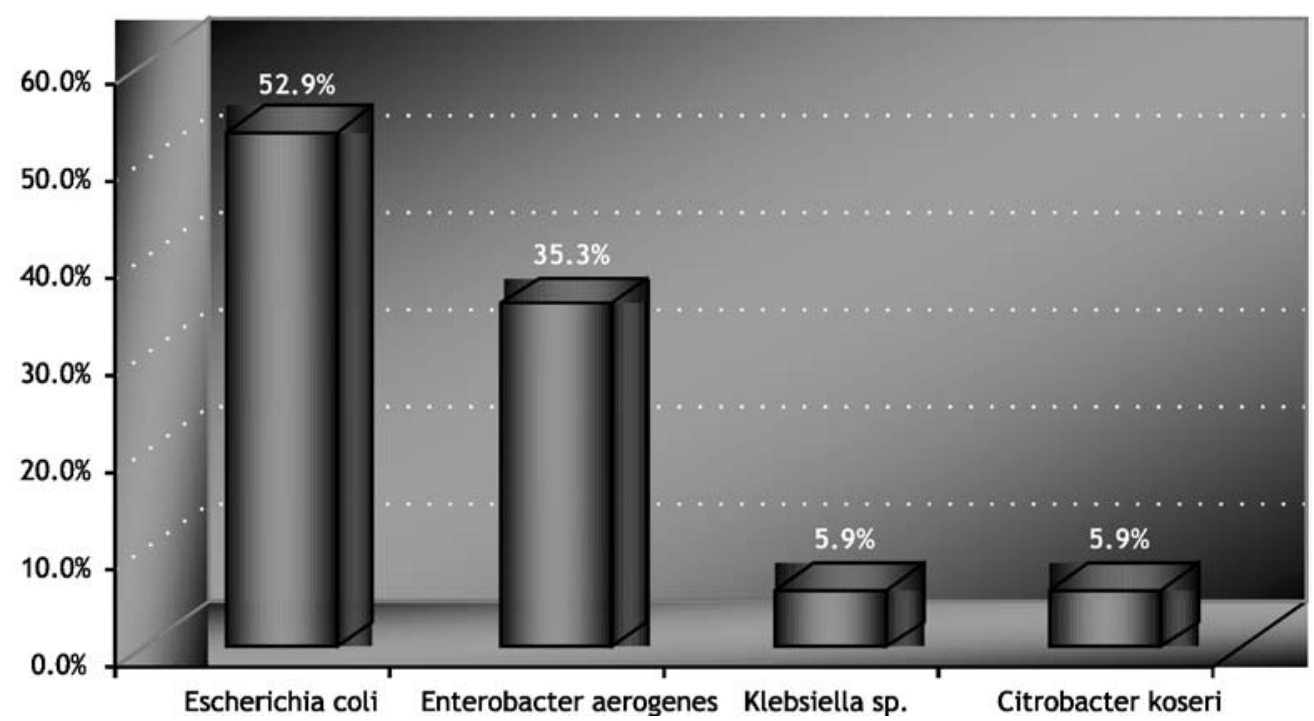

Figura 7. Identificación de microorganismos Gram negativos, baterías bioquímicas antes del inicio de labores en la planta de sacrificio.

En la segunda toma de muestra, la cual se llevó a cabo durante el desarrollo de labores en la planta, se observa que en los tubos de caldo tetrationato no hubo crecimiento, en los de caldo nutritivo se obtuvo crecimiento de flora mixta, conformada según su morfología por cocos Gram positivos, bacilos Gram negativos y bacilos Gram positivos. Las muestras en las cuales se obtuvo desarrollo de flora bacilar Gram negativa, se sembraron en placas de agar Mac Conkey, Endo y XLD para aislamiento. Una vez hecho el análisis de las características macroscópicas y confirmación con la coloración de Gram de la pureza del cultivo y la prueba de oxidasa a los cultivos que lo requerían se procedió a montar las pruebas bioquímicas.
Los resultados obtenidos en las pruebas bioquímicas se observan en la Figura 7.

\section{Discusión}

Según la información recolectada en las encuestas, la mayoría del personal que labora en la planta conoce las normas higiénico-sanitarias, está capacitado y asiste al trabajo en buenas condiciones de salud. Sin embargo, el estudio microbiológico revela fallas en la aplicación de la norma por cuanto se aislaron microorganismos potencialmente patógenos para el humano. En el lavado de manos, que es una disciplina importante en la dinámica de prevención de infección, se observa que 
no hay estandarización en la técnica para el desarrollo de esta rutina y puede ser una de las causas que inducen a la evidencia de contaminación.

El estudio bacteriológico no demostró la presencia de Salmonella spp. en manos ni guantes de los operarios, sin embargo es recomendable realizar estudios de identificación más sensibles que permitan garantizar la ausencia de este microorganismo en las muestras. Se evidenció una variedad significativa de microorganismos patógenos para consumo humano, entre ellos uno de los agentes de estudio Escherichia coli, el cual fue positivo en las dos tomas de muestra.

Es importante considerar que se identificaron otros agentes bacterianos entéricos asociados con cuadros diarreicos e intoxicación alimentaria, probablemente asociados al manejo inadecuado de las buenas prácticas de manipulación, situación que facilita que la flora normal del tracto gastrointestinal, piel y pezuñas de los bovinos y porcinos entren en contacto con la carne en canal y contaminen éstos productos.

Realizar con mayor periodicidad análisis microbiológico en los productos cárnicos así como la identificación de flora microbiana presente en personal manipulador y utensilios empleados en el proceso, con el fin de asegurar todos los estándares de calidad y sanidad necesarios para un producto de consumo masivo y disminuir los índices de enfermedades que afectan el sistema de salud pública y que genera un gasto adicional en el tratamiento de estas enfermedades prevenibles.

Es necesario establecer y hacer cumplir un protocolo especial para el lavado y desinfección de los guantes al comenzar, durante el proceso y al finalizar las labores con el fin de disminuir la probabilidad de contaminación cruzada. Además de cumplir la norma con respecto al uso de todos los elementos de bioseguridad, incluyendo los guantes, independientemente del área en la cual labore el manipulador, con el propósito de disminuir el riesgo de contaminación de los productos cárnicos y evitar enfermedades al operario. Otros factores que se deben considerar en el análisis son la contaminación proveniente por instalaciones físicas en condiciones higiénicas deficientes e inadecuadas o por equipos en mal estado o mal higienizados.
La apropiación de la cultura de producción higiénica, limpia y segura de los productos cárnicos en las plantas de sacrificio y faenado, y el cumplimiento con los objetivos de inocuidad y de desempeño en las plantas de producción cárnica, garantizan una excelente calidad para el consumidor interno, además ofrece competitividad del sector productor a nivel global, con respecto a la exportación a países con los cuales ya se han establecido mercados y con otros como Estados Unidos y en especial a México, deficitarios en este producto. NO

\section{Referencias}

1. Decreto 3075 de 1997. Ministerio de Salud de la República de Colombia.

2. Ley 1122 de 2007. Ministerio de la Protección Social de la República de Colombia.

3. Ministerio de la Protección Social de la República de Colombia. Decreto Número 1500 de Mayo 4 del 2007.

4. Observatorio Agrocadenas. La industria de carnes frescas en Colombia. Colombia: Bogotá; 2005.

5. Samper L. Se reactivan exportaciones de carne bovina. Revista Rumbos Colombia. http://www.rumbosdelperu.com/ rumboscolombia_carnebovina.htm.

6. Rodríguez-Angeles G. Principales características y diagnóstico de los grupos patógenos de Escherichia coli. Salud Pública Mex 2002;44:464-475.

7. Pesca O. Protocolo de vigilancia de enfermedades transmitidas por alimentos. Instituto Nacional de Salud Colombia 2007

8. Cicuta M, Deza N, Roibón W, Benitez M, Ramírez G, Arzú R. Escherichia coli productor de toxina Shiga en reses bovinas y carne molida de Corrientes, Argentina. Rev Argen Vet. 2006:17:20-25.

9. Koneman E. Diagnóstico Microbiológico. Panamericana; 2008 p. $238-248$.

10. Mattar S, Vásquez E. Escherichia coli O157:H7 infection in Colombia. Emerging Infec Dis 1998;4:126-127.

11. Vadillo S, Piriz S, Mateos E. Manual de microbiología veterinaria. Ed. McGraw Hill. Madrid 2002; p. 327-338.

12. Mora Y. Salmonella en porcino: un patógeno alimentario de creciente importancia. Espańa 2003.

13. Flórez R. Epizootiología de las Salmonelosis en bovinos, porcinos y aves. Departamento de Bacteriología, INSTITUNO NACIONAL DE INVESTIGACIONES PECUARIAS México D.F. 1981.

14. Ward LR, Threrlfall J, Smith HR, O'Brien SJ. Salmonella enteritidis Epidemic. Science 2000;287:1753-1756. 